\title{
ACTITUd DE LA PRENSA BRITÁNICA EN LOS PRIMEROS MESES DE LA GUERRA CIVIL ESPAÑOLA (JULIO-DICIEMBRE DE 1936)
}

\author{
Elena OSORIO ALONSO \\ Centro Documental de la Memoria Histórica de Salamanca
}

Recibido: 01/10/2013

Aceptado: 04/11/2013

\begin{abstract}
RESUMEN: Con la llegada de Pablo de Azcárate a la Embajada española en Londres comenzó una importante labor de recogida de información para conocer la actitud de la opinión pública británica respecto a la guerra en España. Con este artículo se pretende recuperar parte de ese material recopilado por el funcionariado de la República española en el Reino Unido y situarlo en un contexto marcado por las graves disensiones entre las potencias europeas.

PALABRAS CLAVE: II República española, guerra civil española, prensa británica, propaganda.

ABSTRACT: With the arrival of Pablo de Azcárate to the Spanish Embassy in London began an important work of information collection to determine the attitude of the British public about the war in Spain. This article aims to recover some of the material collected by the civil service of the Spanish Republic in the UK and to place it in a context marked by serious disagreements among European powers.
\end{abstract}

KEYWORDS: Second Spanish Republic, Spanish civil war, British press, propaganda.

La II República española supuso desde su nacimiento en 1931 un intento de transformación desde un estado caciquil y oligárquico a un régimen parlamentario y constitucional. Fue un intenso periodo de reformas en todos los ámbitos: político, social, económico, militar y religioso. Por ello, por todos estos pasos hacia la modernización de un país, que había vivido al margen de los cambios sufridos por sus vecinos europeos durante las primeras décadas del siglo XX, la República también trajo a primer plano un gran número de tensiones y antagonismos gestados a lo largo de esos mismos años ${ }^{1}$.

${ }^{1}$ Para un acercamiento a la Segunda República y la guerra civil española: Manuel TUÑón DE LARA (1974). La España del siglo XX, vols. 2 y 3. Barcelona: Editorial Laia. 
Estas tensiones dificultaron en gran medida su consolidación, pero no sería hasta el golpe de Estado del 18 de julio de 1936 cuando la República recibió la herida que acabaría siendo mortal tres años más tarde.

Así, con un golpe militar comenzó la guerra civil española. Una guerra en la que se libraron varias y diferentes luchas: un conflicto militar, una lucha de clases, una guerra de religión, una guerra de ideas. Como señala Julián Casanova: «en la guerra civil española cristalizaron, en suma, batallas universales entre propietarios y trabajadores, Iglesia y Estado, entre oscurantismo y modernización, dirimidas en un marco internacional desequilibrado por la crisis de las democracias y la irrupción del comunismo y del fascismo» ${ }^{2}$ y también una lucha por la opinión pública.

La publicación de noticias en la prensa británica sobre la situación política española era una constante desde el triunfo del Frente Popular en febrero de 1936, pero con el estallido de la Guerra civil este hecho se intensificó, convirtiéndose en una verdadera batalla por ganarse el favor de la sociedad.

Esta lucha se entiende en el contexto de una época, iniciada con la Primera Guerra Mundial, marcada por el auge de la propaganda promovida por los Estados y canalizada a través de los medios de comunicación de masas.

La importancia de la opinión pública británica radicaba en el hecho de que Gran Bretaña era todavía la principal potencia europea y marcaba la pauta de los asuntos

Obras específicas sobre la II República: Manuel TuÑón De LARA (1976). La II República. Madrid: Siglo XXI. Julio Gil Pecharromán (2002). Historia de la Segunda República española (1931-1936). Madrid: Biblioteca Nueva.

Sobre los antecedentes sociales y políticos de la guerra civil: Gerald BRENAN (1978). El laberinto español. Barcelona: Ruedo Ibérico.

Resulta también imprescindible la trilogía de Ángel ViÑas (2006). La soledad de la República: El abandono de las democracias y el viraje hacia la Unión Soviética. (2007). El escudo de la República: el oro de España, la apuesta soviética y los hechos de mayo de 1937. (2009) El honor de la República: entre el acoso fascista, la hostilidad británica y la política de Stalin. Barcelona: Crítica.

Para una visión de la guerra en sus antecedentes y fases de una forma concisa: Pierre VILAR (1986). La guerra civil española. Barcelona: Crítica.

De la siguiente obra, mención especial al Ensayo bibliográfico final, que da una visión panorámica de la multitud de escritos sobre la guerra: Paul Preston (2006). La Guerra Civil española. Barcelona: Debate.

2 Julián CASANOva (2007). «República y guerra civil». En Josep FONTANA y Ramón VILLARES (dir.). Historia de España, vol. 8. Barcelona: Círculo de Lectores, p. XVII. 
continentales. Además, su Gobierno fue el principal valedor de la política de no injerencia que afectaría a ambos contendientes ${ }^{3}$.

Así, durante el conflicto español, ambos bandos trataron de influir en la prensa británica con artículos, cartas al director y contactos con propietarios y redactores. Además de intentar controlar las noticias que se difundían a nivel internacional con distintos medios de censura.

Durante el breve periodo analizado en este artículo, se encuentran importantes nombres propios escribiendo sobre la guerra española en periódicos conservadores, como Winston Churchill, el marqués de Merry del Val o Salvador de Madariaga. Mientras, la prensa más progresista cuenta con corresponsales como John Langdon-Davies o Vernon Bartlett e incluso en la prensa comunista su corresponsal Frank Pitcairn (pseudónimo de Francis Claud Cockburn) no duda en enrolarse como miliciano.

Los insurgentes trataron desde el comienzo del conflicto de presentarlo como una sana reacción nacional contra la amenaza del comunismo y como una cruzada en defensa de la religión ${ }^{4}$. Mientras, el Gobierno republicano intentó que se viera como una batalla de la democracia frente al fascismo.

Para defender esta postura y documentar el estado de la opinión pública a través de los medios de comunicación periodísticos y suministrar a esos mismos medios informaciones oficiales, se creó, con el nombramiento de Pablo de Azcárate como embajador español de la República en Londres, el Servicio de Información de la Embajada $^{5}$. Su principal función se centraría en no dar publicidad a los desórdenes del comienzo de la contienda y posteriormente en luchar contra la política de No Intervención defendida por el gobierno británico.

Este servicio llegó a recopilar 29.300 recortes de prensa, principalmente británica, pero también suiza, americana y francesa, organizándolos en 27 series

${ }^{3}$ Hugo GARCía (2008). Mentiras necesarias: la batalla por la opinión británica durante la Guerra Civil. Madrid: Biblioteca Nueva, p. 12.

4 Enrique Moradiellos (2001). «Una guerra civil de tinta: la propaganda republicana y nacionalista en Gran Bretaña durante el conflicto español». Sistema: Revista de ciencias sociales, $\mathrm{n}^{\circ}$ 164, pp. 86-89.

${ }^{5}$ Pablo de Azcárate tomó posesión como embajador el 13 de septiembre de 1936, tras la dimisión de López Oliván, que tuvo lugar el 27 de agosto de ese mismo año. En Enrique MoradiELLOS (1990). Neutralidad benévola. Oviedo: Pentalfa, pp. 198-199.

Sobre Pablo de AzCÁRATE como embajador se pueden consultar sus memorias sobre este período bajo el título Mi embajada en Londres durante la Guerra Civil española. Barcelona: Ariel, 1976. 
temáticas.

Este inmenso conjunto documental, que sirve como base a este artículo, pasó de la Embajada londinense a la sede central del Instituto Cervantes en Alcalá de Henares, desde donde, en 2006, fue trasladado al Archivo Histórico Nacional para su correcta conservación e instalación ${ }^{6}$. Actualmente se encuentra en el Centro Documental de la Memoria Histórica de Salamanca ${ }^{7}$.

Una de las series de este enorme fondo toma el nombre de Attitude of the press y consta de 2.225 artículos. Debido a la amplitud del material y la complejidad de la época, este trabajo se centra en el análisis de los 250 primeros artículos que componen esta serie, los correspondientes al año 1936, el año de inicio de la guerra y también el de mayor repercusión mediática en la prensa británica.

Los periódicos más representativos en este conjunto de recortes de prensa son, sin duda, The Times y The Manchester Guardian, pero también se recogieron artículos de The Daily Telegraph, Daily Herald, News Chronicle, Daily Express, Daily Worker, Evening Standard, The Observer, The Morning Post y Daily Mail.

Como el Servicio de Información de la Embajada no empezó a funcionar hasta comienzos de septiembre de 1936, el grueso de recortes periodísticos utilizados en este trabajo se concentran entre ese mes y finales de año, pero también existen artículos de julio y agosto de los dos diarios más importantes en este conjunto: The Times y The Manchester Guardian.

En cuanto a la ideología e influencia de estos periódicos durante el conflicto español se podrían clasificar, según Tom Buchanan, del siguiente modo ${ }^{8}$. The Times era un diario con una circulación pequeña (200.000 ejemplares), pero una considerable influencia, que sostenía y defendía la política del gobierno conservador británico, aunque sus enviados especiales disfrutaron de una

\footnotetext{
${ }^{6}$ Todos los datos técnicos relativos a la recuperación y restauración de este fondo se encuentran en Juan Ramón Romero Fernández-Pacheco, María Ángela Fernández Olmedo, Nieves del Olmo García, Yolanda Fernández PANAL (2006). «La prensa británica y la Guerra Civil española. Recortes de prensa del Servicio de Información de la Embajada de España en Londres (1936-1939)». Congreso de La Guerra Civil Española 1936-1939.

${ }^{7}$ Todos los recortes de prensa citados en este artículo han sido consultados en el Fondo Embajada de España en Londres, serie Actitud de la prensa, en el Centro Documental de la Memoria Histórica de Salamanca (signatura CDMH, INCORPORADOS, 1508, 1).

${ }^{8}$ Tom Buchanan (1997). Britain and the Spanish Civil War. Cambridge University Press, pp. 24-25. Los datos sobre la tirada de los periódicos han sido tomados de Enrique MorAdiELLOS, «Una guerra civil de tinta...», op. cit., p. 75.
} 
considerable libertad de expresión. El Daily Telegraph (500.000 ejemplares) también apoyaba la política gubernamental en general, pero se mostró crítico con el apaciguamiento de Alemania. Para Hugh Thomas estos dos periódicos se podrían calificar como imparciales ${ }^{9}$.

A la izquierda, hay que hablar del Daily Herald, que contaba con muchos lectores (más de 2 millones de ejemplares) pero escasa influencia. Este diario, editado por la agrupación de sindicatos, era el reflejo de la política del partido laborista, es decir, aunque pro-republicano, inicialmente apoyó la No Intervención.

El Daily Worker, con 400.000 ejemplares, representaba la prensa comunista y prestó su apoyo a la República durante todo el conflicto.

Como prensa liberal se pueden incluir The Manchester Guardian y News Chronicle (1,3 millones de ejemplares), que resultaron ser también más libres en su apoyo a la República y en la condena a los defectos de la política de No Intervención.

Según Hugh Thomas, estos diarios pueden considerarse claramente como partidarios de la República.

Por último, entre los periódicos pro-Franco, se pueden incluir los conservadores Daily Mail, The Morning Post, The Observer y el aislacionista Daily Express. Cabe destacar en los recortes de prensa de esta colección el vocabulario extremo y despectivo utilizado por el Daily Mail para referirse al bando republicano.

\section{LOS HECHOS, SEGÚN LOS RECORTES DE PRENSA ${ }^{10}$}

Desde el triunfo del Frente Popular en febrero de 1936 se acentuó la fractura entre el gobierno republicano y los sectores más conservadores y desde marzo de ese año se tiene noticia de la organización de una conspiración por parte de algunos militares de extrema derecha y la Unión Militar Española (UME). Está documentado que el 8 de marzo hay ya una reunión para «la preparación y desarrollo del Alzamiento Nacional» ${ }^{11}$.

${ }^{9}$ Las referencias a Hugh Thomas se han tomado de José Mario ArMero (1976). España fue noticia: corresponsales extranjeros en la Guerra Civil española. Madrid: Sedmay, p. 147.

${ }^{10}$ Las fechas de los artículos fueron escritas por el personal de la embajada, por lo que en algún caso no se corresponden totalmente con la fecha correcta de publicación, pudiendo existir entre ambas un margen de algunos días.

${ }^{11}$ Julián CASANOVA, República y guerra civil, op. cit., p. 173. 
Se acuerda que la sublevación iba a ser encabezada por el general Sanjurjo, que se encontraba en Portugal, pero, durante los preparativos, el verdadero protagonista será el general Mola.

Ya desde las primeras instrucciones sobre la manera de llevar a cabo la sublevación, el general Mola deja muy clara la necesidad de actuar con extrema violencia, algo que la prensa británica reflejará a lo largo de los primeros meses de guerra, con continuos llamamientos a la humanización del conflicto. Según Mola «se tendrá en cuenta que la acción ha de ser en extremo violenta para reducir lo antes posible al enemigo, que es fuerte y bien organizado. Desde luego serán encarcelados todos los directivos de los partidos políticos, sociedades o sindicatos no afectos al Movimiento, aplicándose castigos ejemplares a dichos individuos para estrangular los movimientos de rebeldía o huelgas» ${ }^{12}$.

Finalmente, en la madrugada del 18 de julio, el general Franco se pronuncia contra el Gobierno de la República.

Las noticias en los primeros días tras el golpe del 18 de julio hablan de revuelta o rebelión en España ${ }^{13}$, pero ya en sus titulares del 22 y 24 de julio The Manchester Guardian menciona la palabra «conflicto»y el aumento del riesgo de una guerra ${ }^{14}$. Mientras, The Times, en un recorte del 27 de julio, hace referencia ya a la guerra civil en Sevilla y un día después utiliza la palabra «tragedia» para definir la situación española ${ }^{15}$.

La utilización del término «tragedia» para referirse a la realidad española se mantiene durante el mes de agosto en esa publicación y aparece también en The Manchester Guardian ${ }^{16}$. Ambos periódicos coinciden además en hacer, a finales de ese mismo mes, un llamamiento al humanitarismo en el desarrollo de la guerra ${ }^{17}$.

Desde estos primeros momentos, todavía tan confusos, se aprecian grandes diferencias en la manera de enfocar el problema español en ambos diarios. The Times ve el fin de la democracia tanto si vence el gobierno como los rebeldes, pues

\footnotetext{
12 Ibídem, p. 174.

13 «Revolt in Spain», Manchester Guardian, 20-VII-1936 y «Spanish Rebellion», The Times, 21VII-1936.

14 «Spanish Conflict»y «Spanish War Risks Advance», Manchester Guardian, 22 y 24-VII-1936.

15 «Civil War in Sevilla»y «The Spanish Tragedy», The Times, 27 y 28-VII-1936.

16 «Tragedy of Spain», The Times, 5-VIII-1936, y «Spanish Tragedy», Manchester Guardian, 6VIII-1936.

17 «Spain. An appeal», Manchester Guardian, 22-VIII-1936, y «Horrors of Civil War», The Times, 28-VIII-1936.
} 
considera que el gobierno republicano está preso de sus socios marxistas ${ }^{18}$, mientras que The Manchester Guardian considera el gobierno republicano como un gobierno legal, elegido por el pueblo, que no debe ser puesto al mismo nivel que los que se han levantado en su contra.

Estas opiniones vienen alimentadas por la creciente publicación de artículos en los medios británicos sobre la conflictividad en España desde la victoria del Frente Popular en febrero de $1936^{19}$. La sensación de que los meses previos a la guerra habían sido la antesala de una revolución comunista estaba bastante extendida en la prensa británica y no solo en los medios más conservadores, también era compartido por estos periódicos más moderados de los que ahora se trata ${ }^{20}$.

Así, mientras en artículos y cartas al director del Manchester Guardian se defiende la necesidad de apoyar al Gobierno republicano por parte de Gran Bretaña $^{21}$, The Times se postula desde el primer momento como un firme defensor de la política de No Intervención propuesta por Francia y secundada por el Gobierno británico ${ }^{22}$.

La posición de neutralidad radical del Gobierno británico se inscribe dentro de la política general de apaciguamiento en Europa, que se había adoptado desde la crisis de 1929, pero también estuvo determinada por la convicción de los gobernantes británicos de que España, desde las elecciones de febrero de 1936,

18 «The Spanish Climax», The Times, 21-VII-1936. Peligro de gobierno comunista y anarquista en «Ruthlessness in Spain», The Times, 3-VIII-1936.

19 Miguel Fernández-Longoria (2005). «La percepción de los acontecimientos políticos españoles de enero a julio de 1936 en la prensa inglesa». Espacio, Tiempo y Forma, Serie V, Historia Contemporánea, t. 17, pp.191-205.

${ }^{20}$ Para un análisis profundo y desmitificado de la situación de «violencia» en la España prebélica destaca José Luis LedeSMA (2013). «La primavera trágica de 1936 y la pendiente hacia la guerra civil». En Francisco SÁnCHez PÉREZ (coord.). Los mitos del 18 de julio. Barcelona: Crítica, pp. 313339.

21 «Spanish Tragedy» y «The Future of Spain», Manchester Guardian, 6 y 12-VIII-1936. También una carta al director de George E. G. Catlin titulada «Civil War in Spain», VIII-1936.

22 «Collective Neutrality», «The powers and Spain» $\mathrm{y}$ «Europe and Spain», The Times, 10, $15 \mathrm{y}$ 21-VIII-1936.

El propio embajador español, Pablo de AzCÁRATe, en Mi embajada en Londres, op. cit., p. 43, señala este diario como un apoyo sin reservas a la política de apaciguamiento seguida a nivel internacional por el gobierno británico antes de la II Guerra Mundial. Siendo la no intervención en la guerra española una parte de esta política. Algunos políticos conservadores no estaban de acuerdo con esta política internacional, como fue el caso de Churchill o Eden. 
estaba inmersa en un proceso similar a la crisis rusa de 1917, es decir, un gobierno liberal-burgués desbordado por los bolcheviques ${ }^{23}$.

Por ello, en un intento por confinar la lucha española dentro de sus fronteras y que no se acabara convirtiendo en una guerra general europea, desde principios de agosto se está intentando un Acuerdo de No Intervención de las potencias europeas en la Guerra civil española, a instancias de Francia y Gran Bretaña, y, finalmente, entra en vigor el 24 de agosto de 1936 con la adhesión de Alemania. Forman parte del acuerdo 27 estados europeos que se comprometen a prohibir la venta, envío o tránsito de armas y municiones con destino a ambos bandos de la contienda española ${ }^{24}$.

Este tema se convertirá en uno de los protagonistas de los artículos de la prensa británica durante el mes de septiembre. El principal abanderado de esta política seguirá siendo The Times, que cree necesaria la constitución de un comité que supervise dicho acuerdo ${ }^{25}$; comité que celebrará su primera reunión el 9 de septiembre en Londres.

Ese mismo mes, con la llegada del nuevo embajador republicano, Pablo de Azcárate, y la creación del Servicio de Información mencionado anteriormente, ya se recogen más recortes de prensa relativos al conflicto español.

Según cálculos del Ministro de Estado, Julio Álvarez del Vayo, sólo el 10\% de los diplomáticos españoles permanecieron leales a la República después del golpe militar de julio ${ }^{26}$.

Dentro de esa mayoría pro-franquista hay que encuadrar también al embajador en Londres, Julio López Olivan, y sus principales colaboradores, quienes permanecieron en sus cargos hasta finales de agosto de $1936^{27}$. El hecho de no dimitir inmediatamente, como hicieron otros embajadores, sólo hizo que dañar y dificultar en lo posible todas las gestiones de República con el gobierno británico. Consiguió boicotear la venta de armamento para la República y no dimitió hasta que el 19 de agosto entró en vigor el embargo de armas a España.

${ }^{23}$ Enrique Moradiellos (1996). «Una misión casi imposible: la embajada de Pablo de Azcárate en Londres durante la Guerra Civil (1936-1939)». Historia contemporánea, n 15, p. 129.

24. Enrique Moradiellos, Neutralidad Benévola, op. cit., pp. 243-244 y Enrique Moradiellos (2004). 1936. Los mitos de la guerra civil. Barcelona: Península, p. 158.

25 «Havoc in Spain», The Times, 4-IX-1936.

${ }^{26}$ Enrique Moradiellos, Neutralidad Benévola, op. cit., p. 191.

${ }^{27}$ El doble juego de López Oliván en Ángel ViÑas (2006). La soledad de la República. El abandono de las democracias y el viraje hacia la Unión Soviética. Barcelona: Crítica, pp. 74-77. 
Además, el Reino Unido tenía una importante representación de monárquicos alfonsinos que desde el principio apoyaron el golpe y crearon una Junta que se convirtió en la representación oficiosa de los rebeldes. Este grupo, formado por personas muy influyentes, ayudó desde un principio a los rebeldes con propaganda política entre las élites y con la compra de aviones civiles.

El nombramiento de Pablo de Azcárate y Flórez como nuevo embajador de la República tuvo un gran alcance político, pues se trataba de una persona de reconocido prestigio internacional que ostentaba el cargo de secretario general adjunto de la Sociedad de Naciones. Al ser una persona de conocida ideología liberal, el Gobierno británico no pudo negarle el «placet», lo que supuso todo un triunfo de la República ante un gobierno conservador como el británico, que no la veía con buenos ojos ${ }^{28}$.

Aun así, la principal tarea del nuevo embajador -ganar para la República el mayor apoyo y comprensión posible entre las clases conservadoras inglesasresultó del todo imposible.

Con esta nueva situación diplomática, ya se pueden apreciar muy diversas opiniones periodísticas sobre la postura que debería tomar el Gobierno británico. Así, The Times se mantiene como el principal valedor de la política gubernamental de No Intervención, pero también consideran que es necesario mantenerse al margen de esa lucha fratricida los conservadores The Morning Post y Daily Express $^{29}$. El ultraderechista Daily Mail va más allá al considerar necesario el aislamiento y el rearme británico ${ }^{30}$.

En el otro extremo se encuentra el News Chronicle que, tras comparar la respuesta de las potencias fascistas a los requerimientos de Francia y Gran Bretaña para cumplir la política de No Intervención con el avance de un caracol, en un artículo de Vernon Bartlett defiende la necesidad de tomar partido en la guerra de España a favor del Frente Popular, pues su defensa es la defensa de la democracia $^{31}$. El Daily Worker también arremete contra la política de neutralidad,

${ }^{28}$ Pablo de AzCÁRATE, Mi embajada.., op. cit., pp. 24-27.

29 «Issues in Spain», The Morning Post, 5 de septiembre de 1936; «Opinion», Daily Express, 5IX-1936. El Daily Express irá avanzando hacia posiciones cada vez más aislacionistas, como se refleja en un artículo del 23-XII-1936, titulado «Spain for Spaniards».

30 «Keep clear of war», Daily Mail, 5-IX-1936.

31 «The pace of the snail» $\mathrm{y}$ «Democracy must not commit suicide», News Chronicle, 7 y 10-IX1936. 
pues hace que los milicianos no tengan armas ni para instruirse ${ }^{32}$.

Otras noticias recogidas durante septiembre en los recortes de prensa de esta colección se refieren a avances militares como la caída de Irún y San Sebastián o la toma de Toledo.

Tras unos días en los que parecía que en el Frente Norte la situación se mantenía en tablas, tiene lugar la caída de Irún en manos de los insurgentes el 2 de septiembre y once días después también será tomada San Sebastián, provocando diferentes titulares en la prensa británica. Así, mientras el Daily Herald considera que en la toma de Irún se produjo una masacre, el Daily Mail considera la toma de esta ciudad por los «patriotas» como una gran noticia para la causa de la libertad en España y Europa y una importante victoria para la Cristiandad, el orden y la decencia ${ }^{33}$.

A finales de ese mismo mes se produce la toma de Toledo por las tropas moras, lo que, según The Manchester Guardian, es celebrado por la prensa británica prorebelde. The Daily Telegraph también hace mención a la caída de esta ciudad, pero como señal del avance imparable de los insurgentes hacia Madrid ${ }^{34}$.

En general, los medios británicos se refieren a los dos bandos en lucha como «leales o Gobierno» e «insurgentes o rebeldes», aunque hay algunas variantes en las que se define a los sublevados como «derecha», «Junta» o incluso «patriotas», pero es significativo el hecho de que ningún medio, ni los más conservadores, se refieran a las partes del conflicto como «rojos» y «nacionales», términos cuya utilización se ordena desde la Junta de Burgos y que, como se aprecia en los artículos de esta colección, salvo contadas excepciones, no tiene un efecto destacable en la prensa británica ${ }^{35}$.

También tiene gran repercusión en los medios británicos el nombramiento a principios de septiembre de un nuevo gobierno en España, con Francisco Largo Caballero, líder del socialismo revolucionario, al frente. El Daily Express lo define como «jefe de la España roja» y considera que, con su llegada al poder, se aprecia claramente quiénes mandan en España: los comités de defensa anarquistas,

${ }^{32}$ En un artículo de 26-IX-1936 de Frank Pitcairn, enrolado como miliciano.

33 «Irun» y «Keep clear of war», Daily Herald y Daily Mail, 5-IX-1936.

34 «The manacles of Toledo» y «The drive for Madrid», Manchester Guardian y The Daily Herald, 28-IX-1936.

${ }^{35}$ Hugo García, Mentiras necesarias.., op. cit., p. 48. 
socialistas y comunistas $^{36}$. El Daily Mail va más allá y señala que el nuevo gobierno está compuesto por «sinvergüenzas y violentos comunistas»» ${ }^{37}$.

Estas opiniones son consecuentes con la visión de la prensa conservadora británica de Francisco Largo Caballero como «el Lenin español». Ya desde antes de la guerra estos medios se lamentaban de que el partido socialista español hubiera abandonado la línea evolucionista y moderada de Fernando de los Ríos, por ejemplo, para dar paso a la vía revolucionaria, defendida por Caballero ${ }^{38}$.

Las reacciones a este nuevo gobierno son mucho más moderadas por parte de The Times, que lo cree más representativo ${ }^{39}$. También The Manchester Guardian habla de este asunto, pero centrándose en las tareas que se esfuerza por desempeñar el nuevo gabinete: el intento de coordinación de la actividad militar y la necesidad de mejorar las comunicaciones ${ }^{40}$.

Desde el inicio de la guerra hasta septiembre, en Madrid el poder había estado en manos de un gobierno republicano moderado liderado por José Giral. Este gobierno trataba de dar la imagen de continuidad republicana ante el extranjero, pero la verdad es que carecía de autoridad real sobre los numerosos poderes nacidos de la espontaneidad popular. Por ello, pronto se hizo necesario formar un gobierno más acorde con las fuerzas sindicales y antifascistas en lucha ${ }^{41}$.

El gobierno formado por Largo Caballero el 4 de septiembre de 1936 responde a estas necesidades de mayor representación, pero hasta noviembre no conseguirá que los anarquistas también participen en él.

Durante este mes de septiembre, The Manchester Guardian inaugura además una serie de artículos quincenales que van a ir actualizando, día por día, la situación en los frentes de la guerra española, que poco a poco se va convirtiendo en una lucha de larga duración.

El 26 de septiembre se recoge en varios diarios la noticia del discurso pronunciado en la Sociedad de Naciones por Anthony Eden, secretario de Estado

36 «Opinion», Daily Express, 5-IX-1936.

37 «Keep clear of war», Daily Mail, 5-IX-1936.

38 Miguel FernÁNDEZ-LONGORIA, «La percepción de los acontecimientos...», op. cit., pp.191205.

39 «Europe and Spain», The Times, 8-IX-1936.

40 «Spanish Civil War. Diary or Events», Manchester Guardian, 19-IX-1936.

${ }^{41}$ Pierre VILAR (1986). La guerra civil española. Barcelona: Crítica, p. 105. 
para Asuntos Extranjeros (Foreign Office). ${ }^{42}$. Se trata de una noticia no directamente relacionada con la guerra española, pero considerada de interés por el Servicio de Información de la Embajada, ya que la Sociedad de Naciones era el mecanismo internacional al que intentará acudir el Gobierno republicano español para defenderse ante la negativa a ser escuchado directamente por los gobiernos de los países europeos.

La opinión que merece este discurso varía según el periódico. Mientras el Daily Herald lo considera lleno de coraje e iniciativa, así como de fe en la democracia y en la Sociedad de Naciones, algo que comparte el Daily Telegraph, la opinión del News Chronicle es muy diferente ${ }^{43}$. Este diario lo considera muy poco concreto, pues cree que debería haber ido más allá a la hora de definir la actitud británica si pretende reavivar la Sociedad como fuerza importante en asuntos internacionales.

En el mes de octubre toma protagonismo el avance de las tropas rebeldes hacia Madrid, algo que ya se apuntaba a finales del mes anterior con la toma de Toledo y el peligro que corrían las comunicaciones de la capital con Valencia.

Cada vez parece más próxima la caída de la capital a manos de las tropas rebeldes y esto se refleja de una manera constante en la prensa británica. Ya a comienzos de mes The Times se refiere al cerco casi completo de la capital, mientras The Manchester Guardian habla de las débiles defensas de las que dispone la ciudad y de la calma con la que se espera el ataque definitivo ${ }^{44}$. A mediados de octubre el Daily Telegraph considera que se acerca un momento decisivo de la guerra, pero no cree ya tan fácil la toma de Madrid, gracias al renovado espíritu que ha traído el nuevo gobierno de Largo Caballero ${ }^{45}$. Sin embargo, a finales de mes, The Manchester Guardian señala la situación de los rebeldes a tan solo doce millas de la capital y el conservador The Morning Post cree que la toma de la capital por «las fuerzas de la Junta» no puede retrasarse mucho $^{46}$.

42 Según Pablo de AzCÁRATE en Mi Embajada..., op. cit., pp. 39-40, era una persona que sentía repugnancia por el régimen franquista, pero esto no se tradujo en una actitud favorable hacia la República. Para Azcárate, un rasgo distintivo de su carácter era la indecisión.

43 «Mr. Eden's speech», «At last a policy» y «Hurrying slowly», Daily Herald, Daily Telegraph y News Chronicle, 26-IX-1936.

44 «Approaching Madrid», The Times, 1-X-1936; «The defence of Madrid» y «Madrid awaits attack with calmness», Manchester Guardian, 14-X-1936.

45 «Spain's fate on the eve of decision», Daily Telegraph, 15-X-1936.

46 «Twelve miles from Madrid», Manchester Guardian, 27-X-1936, e «Intervention with a difference», The Morning Post, 21-X-1936. 
Junto a la lucha por la capital, también se convierte en tema recurrente de la prensa el incumplimiento del Acuerdo de No Intervención. La mayoría de los diarios critican la ayuda que están recibiendo los insurgentes por parte de las potencias fascistas, lo que rompe claramente el acuerdo defendido por Gran Bretaña y Francia ${ }^{47}$. Incluso el progubernamental en materia de no intervención, The Times, critica la falta de capacidad ejecutiva de la Sociedad de Naciones ante esta situación internacional ${ }^{48}$.

Aunque la ayuda activa de las potencias fascistas a los rebeldes es clara, el Gobierno británico defiende el mantenimiento del acuerdo por falta de evidencias $^{49}$. Junto al Gobierno republicano, la URSS será uno de los principales denunciantes de ese incumplimiento, proponiendo que exista el derecho a dar armas a Madrid ante la nueva situación ${ }^{50}$.

En todo este asunto, Vernon Bartlett, del News Chronicle, será el único que se refiera a la posible ayuda de Moscú, rompiendo también el Acuerdo de No Intervención, como un verdadero estímulo para la defensa de la ciudad de Madrid $^{51}$.

En este punto de clara inutilidad de la política de No Intervención, se produce un hecho muy significativo que va a condicionar el alargamiento de la contienda: Stalin apoya la formación de las Brigadas Internacionales y comienza a enviar suministros de material bélico a la República ${ }^{52}$. Con esta nueva ayuda, que, de todos modos, resulta intermitente y totalmente incomparable con la ayuda germano-italiana a los rebeldes, se consigue un cierto equilibrio de fuerzas que contribuirá a la heroica resistencia de Madrid $^{53}$.

47 «Defences of Madrid», The Times, 21-X-1936; «A need for evidence» y «Twelve miles from Madrid», Manchester Guardian, 2 y 27-X-1936; «Spain after three months' warfare», Daily Worker, 20-X-1936; «Spain's fate on the eve of decision» y «Russia darkens the outlook», Daily Telegraph, 15 y $24-X-1936$.

48 «Excesses in Spain», The Times, 8-X-1936.

49 «A need for evidence», Manchester Guardian, 2-X-1936.

50 «Russia darkens the outlook», Daily Telegraph, 24-X-1936.

51 «Tonic for Madrid», News Chronicle, 8-X-1936.

52 Enrique Moradiellos, 1936. Los mitos..., op. cit., p. 162.

53 Sobre la ayuda de las potencias fascistas a los rebeldes, el abandono de las democracias y el apoyo de la URSS, aunque con dificultades, a la República, Ángel ViÑAS (2006). La soledad de la República.., op. cit.

Datos concretos de armamento y contingentes de hombres en Ángel ViÑAS (2012). «Los apoyos exteriores, palancas de la victoria y de la derrota». En Ángel ViñAS (ed.). En el combate por la Historia. La República, la guerra civil, el franquismo. Barcelona: Pasado y Presente, pp. 251-263. 
Con la intervención soviética también se da al traste con la idea británica de que el conflicto acabara pronto, una de las principales esperanzas que habían guiado la conducta de los gobernantes británicos durante estos primeros meses de Guerra civil española ${ }^{54}$.

Ante la creciente presión insurgente sobre la capital y el alargamiento de la guerra, existe un llamamiento generalizado para evitar masacres indiscriminadas, llamamiento presente ya en la prensa británica desde el comienzo de la contienda. Por ello, para aliviar un poco esta difícil situación, el Gobierno británico se ofrece como mediador para el intercambio de prisioneros ${ }^{55}$.

Los meses siguen pasando y en noviembre la batalla por Madrid sigue siendo la protagonista de las noticias sobre la Guerra civil española. La resistencia de la capital, su defensa, su conversión en un símbolo e incluso hipótesis sobre qué ocurrirá si es tomada por los rebeldes copan la mayor parte de los artículos sobre el tema español en las publicaciones periódicas británicas.

Los primeros días del mes las informaciones se centran en el traslado del gobierno a Valencia, hecho que sucede el 6 de noviembre ${ }^{56}$. Este suceso se analiza de diferentes modos en la prensa británica. Mientras el News Chronicle habla de una sabia decisión del gobierno republicano, que le permitirá reorganizarse lejos de la presión rebelde sobre Madrid. La prensa más conservadora habla de este traslado como de un abandono de su puesto por parte del gabinete republicano, lo que augura una pronta victoria insurgente.

Según Pierre Vilar, «este traslado no era nada deshonroso para un gobierno prudente, decidido a continuar la lucha» ${ }^{57}$, pero, incluso entre personas cercanas a Largo Caballero, se vio con cierto derrotismo, sobre todo porque sólo se designaron dos generales, Pozas para el frente centro y Miaja para la defensa de la capital, ayudados por una Junta, cuya composición quedo solamente sugerida a la salida del gobierno.

Pero el mes avanza y lo que parecía una inminente toma de la capital española por los insurgentes se retrasa. Ante esta situación se produce una importante noticia

${ }^{54}$ Paul Preston (ed.) (1999). La República asediada. Barcelona: Península, p. 29.

55 «Defences of Madrid», The Times, 21-X-1936; «Intervention with a difference», The Morning Post, 21-X-1936; «Gen. Franco bringing up siege guns», Daily Telegraph, 21-X-1936.

56 «Last Hours in Madrid», The Times, 8-XI-1936; «The fate of Madrid», Manchester Guardian, 8-XI-1936; «A wise decision», News Chronicle, 8-XI-1936; «He left the post», Daily Express, 9-XI1936; «The flight from Madrid», Daily Telegraph, 9-XI-1936.

${ }^{57}$ Pierre VILAR, La guerra civil..., op. cit., p. 105. 
a nivel político y diplomático: el reconocimiento por parte de Alemania e Italia de la Junta de Burgos como gobierno legítimo de España el 18 de noviembre de $1936^{58}$. Este hecho puede ser considerado como la respuesta de las potencias fascistas al compromiso soviético con la República española y su éxito en la batalla de Madrid. Además, con esta noticia se completa el proceso de internacionalización de la guerra española y se echa por tierra cualquier eficacia real del Comité de No Intervención ${ }^{59}$.

A finales de ese mismo mes es destacable que el Daily Telegraph se haga eco de las muertes de Buenaventura Durruti y Emiliano Barral, líderes anarquistas, en el frente de Madrid (20 y 21 de noviembre de 1936$)^{60}$. Se trata de una noticia importante para la lucha interna española, pero sin ninguna repercusión en la política británica, por lo que resulta cuanto menos curioso que aparezca reflejada en tan importante medio de comunicación.

En el último mes del año la batalla por Madrid sigue siendo el tema central de las noticias sobre España en la prensa británica. La ofensiva sobre la capital se alarga en el tiempo y la situación de sus habitantes se agrava: falta de provisiones, dificultades en evacuación y preocupación por el destino de los prisioneros quedan reflejadas en los periódicos británicos ${ }^{61}$.

Por su parte, los diarios conservadores The Observer y Morning Post aportan su particular visión de la guerra española. El primero señala, con acierto, que la guerra civil se ha convertido en una guerra internacional disfrazada, pero opina que han sido los rusos los primeros en infringir el acuerdo de no intervención, algo totalmente discutible ${ }^{62}$. En cuanto al Morning Post, sigue presentando la zona bajo mando republicano como una zona dominada por el miedo ${ }^{63}$, algo cada vez más

58 «Spain and Europe», Manchester Guardian, 23-XI-1936; «The Spanish Cauldron», Morning Post, 20-XI-1936; «Opinion: big and little fish», Daily Express, 19-XI-1936; «League must meet», Daily Herald, 20-XI-1936; «Democracy is also de target», Daily Worker, 23-XI-1936; «Gen. Franco's naval forces to enforce blockade», Daily Telegraph, 20-XI-1936. Enrique MoRADIELLos, Neutralidad benévola, op. cit., p.333.

${ }^{59}$ Enrique MoRAdiEllos, 1936. Los mitos..., op. cit., p. 163.

60 «Leaders killed on Madrid front», Daily Telegraph, 23-XI-1936.

61 «The besieged capital» «Lawlessness in Madrid» «Refugees from Madrid», The Times, 1, $8 \mathrm{y}$ 21-XII-1936; «The fate of Madrid», Manchester Guardian, 5-XII-1936; «Spain's agony», News Chronicle, 9-XII-1936; «Winter in Madrid» y «Christmas, Madrid», Daily Express, 14 y 23-XII1936.

62 «Madrid as victim», The Observer, 6-XII-1936.

63 «Spanish regimes contrasted», Morning Post, 8-XII-1936. 
incierto con el avance de la guerra y la toma de control gubernamental efectivo sobre su territorio.

Además, a pesar de llevar poco más de dos meses en funcionamiento, el Acuerdo de No Intervención y su comité ya se confirman por una parte de la prensa como totalmente inoperantes. Así, el News Chronicle, que desde el principio abogaba por una intervención a favor de la República, habla del sinsentido de la no intervención cuando Alemania está enviando tropas. Este periódico opina que las democracias deberían tomar partido, porque la actuación alemana amenaza directamente la paz europea ${ }^{64}$.

También continúa, como en meses anteriores, la preocupación internacional por el destino de los prisioneros y siguen los intentos de mediación internacional para que exista un intercambio ${ }^{65}$.

Con el cambio de año queda claro que lo que parecía que iba a ser una breve lucha se ha transformado en una guerra de larga duración en la que intervienen fuerzas internacionales y en la que las democracias europeas mantienen los ojos cerrados, aferrándose a la farsa de la No Intervención, para no ayudar a una república legalmente constituida a la que temen.

\section{CONCLUSIONES}

Estos primeros meses de Guerra civil en España aparecen reflejados de una manera muy intensa en la prensa británica, debido principalmente a las implicaciones internacionales del conflicto en la convulsa situación europea de los años 30 .

El conflicto español afectaba de una manera muy directa a la política de apaciguamiento internacional que estaba llevando a cabo el gobierno conservador británico, por lo que era de esperar que los medios de comunicación se hicieran eco de todo lo relativo a los sucesos de España.

El protagonismo de estos meses en la prensa, tras el caos inicial, posterior al levantamiento, se centra en la resistencia de Madrid y en la organización de la política internacional de No intervención. Aunque también hay un gran interés en la humanización de la guerra, pues estos primeros meses resultan un tanto confusos

64 «Call the bluff», News Chronicle, 21-XII-1936.

65 «The besieged capital» y «Lawlessness in Madrid», The Times, 1 y 8-XII-1936; «Mediation in Spain», Daily Herald, 15-XII-1936; «Mediation for Spain» y «Hostages to be exchanged», Daily Telegraph, 4 y 22-XII-1936. 
en la zona republicana, donde el gobierno intenta poco a poco recuperar su capacidad de mando y evitar represalias. El llamamiento a humanizar la contienda también se refiere a la zona controlada por los rebeldes, aunque, en este caso, la represión será desde el comienzo totalmente calculada y organizada por los mandos militares $^{66}$.

La defensa de Madrid se convirtió en un verdadero símbolo de resistencia popular que aun hoy perdura con el grito de «no pasarán» y su protagonismo en la prensa británica durante todo el otoño de 1936 refleja el carácter heroico y luchador del pueblo madrileño, frente a todas las adversidades: falta de armas, de formación militar, de suministros. Sin duda, las noticias sobre la situación de Madrid son las más numerosas en la selección de recortes de prensa a la que se hace referencia en este trabajo.

El otro gran foco de atención en los medios británicos durante estos primeros meses de Guerra civil española, se encuentra en el Acuerdo de No Intervención y la inoperancia del Comité que se encargará de llevarlo a cabo. Mes a mes se va observando en la prensa su carácter dilatorio en la toma de decisiones y en definitiva su total falta de efectividad para acabar con la ayuda de las potencias fascistas a los insurgentes españoles.

Poco a poco, según se va viendo que el conflicto se alarga, el interés de la prensa internacional en el conflicto español irá disminuyendo, pero en estos primeros meses de incertidumbre y primeros pasos diplomáticos y militares, las noticias sobre España tendrán un lugar central en la prensa británica.

Además de hablar de los hechos reflejados en la prensa británica, algo por otra parte muy estudiado y analizado por grandes autores, con este artículo se pretende sobre todo dar visibilidad a una pequeña parte de un inmenso conjunto de noticias recopiladas y organizadas por la Embajada española en Londres. Como ya se señaló al comienzo de este trabajo, los funcionarios del Servicio de Información recopilaron cerca de 30000 recortes de prensa, pero no sólo eso, si no que, además, los organizaron en 27 series temáticas, que creo que pueden ser muy interesantes

${ }^{66}$ Enrique MoRAdiellos (1996). La Perfidia de Albión, el Gobierno británico y la guerra civil española. Madrid: Siglo XXI, pp. 40-41, habla de la implacable represión en el territorio militarizado de la España insurgente, frente al colapso parcial de las instituciones que debilitó al gobierno en la España republicana.

La represión durante la Guerra Civil española está analizada con todo detalle en Paul PRESTON (2011). El holocausto español. Barcelona: Círculo de Lectores. 
para poder investigar aspectos concretos del conflicto español ${ }^{67}$. No es solamente un trabajo de hemeroteca, ya que se basa en una organización subjetiva, que me parece imprescindible para conocer el conflicto desde la perspectiva de unos de sus muchos protagonistas.

Se trata pues de una ingente labor de documentación e información realizada por unas pocas personas que permanecieron leales a la República española en un momento en el que la mayor parte del cuerpo diplomático desertó y es una suerte que, tras múltiples vicisitudes, esta documentación haya podido llegar hasta nosotros.

${ }^{67}$ Títulos de algunas de las series mencionadas: Non-Intervention, Rebel Policy, Progress of the War, Evacuation of Civilians, Incidents at the Sea, Italy, Germany, Culture versus the War. 